Article

\title{
Periodate Oxidation of Methylcellulose: Characterization and Properties of Oxidized Derivatives
}

\section{Marguerite Rinaudo}

Centre de Recherches sur les Macromolecules Végétales (CERMAV-CNRS) affiliated with Joseph Fourier University, BP53, 38041 Grenoble Cedex 9, France;

E-Mail: marguerite.rinaudo@cermav.cnrs.fr; Tel.: +33-476037627; Fax: +33-476547203

Received: 23 August 2010; in revised form: 19 October 2010 / Accepted: 28 October 2010 /

Published: 29 October 2010

\begin{abstract}
In this paper, the behavior of oxidized methylcelluloses is compared with that of the initial methylcellulose, an amphiphilic cellulose derivative. Methylcelluloses are important for many applications in the cosmetic and food industries. The mechanism of thermo-gelation of methylcellulose is briefly explained as well as the method of oxidation of polysaccharides. Then, our experiments involve the preparation of oxidized methylcelluloses: three degrees of oxidation are prepared and the new polymers are characterized by NMR, IR, SEC and rheology. Oxidation with periodate theoretically allows introduction of two aldehydic groups on $\mathrm{C} 2-\mathrm{C} 3$ glycol positions of anhydroglucose units. This reaction not only enhances the flexibility of the cellulosic backbone, but also causes a decrease in the molecular weight. In particular, the rheological behavior of methylcellulose and oxidized methylcellulose as a function of temperature is examined. The oxidized methylcelluloses prepared, being rich in aldehyde functions, become interesting intermediaries to prepare new cellulose derivatives. In this paper, three examples of reductive amination based on the reaction of modified methylcelluloses and $-\mathrm{NH}_{2}$ groups of different molecules are described: $\beta$-alanine produces a polyelectrolyte; chitosan and hyaluronan-ADH (derivative obtained with adipic dihydrazide allowing introduction of $-\mathrm{NH}_{2}$ functions on $\mathrm{HA}$ backbone) are crosslinked and give new biocompatible hydrogels.
\end{abstract}

Keywords: oxidized methylcellulose; reductive amination; crosslinkage of chitosan; crosslinkage of hyaluronan 


\section{Introduction}

Methylcelluloses are important cellulose ether derivatives which become water soluble in an intermediate range of substitution degree DS (with $1.4<\mathrm{DS}<2.5$ ) with an amphiphilic character and associative properties. The limits of water solubility depend on the distribution of methyl substituents along the cellulosic backbone on C-2, C-3 and C-6 positions [1]. Water soluble commercial samples are block-wise derivatives with an average DS in the range of 1.7 with highly methylated zones corresponding to the reaction of amorphous regions of cellulose in the heterogeneous conditions adopted by industry for methylation. The original behavior of such polymers is that a sol-gel transition is obtained when temperature increases (over around $60^{\circ} \mathrm{C}$ ) in relation to their microstructure [2], consisting of heterogeneous chains made of highly substituted zones which are hydrophobic, and less substituted zones rich in $-\mathrm{OH}$ groups yet still hydrophilic [1]. Methylcelluloses are mainly used as a food additive (under reference E461) or in cosmetics for their thickening and emulsifier properties. Nevertheless, in spite of their important applications, their mechanism of gelation was discussed for a long time in the literature [3,4] and our group participated in this debate [1,2,5-7]. For this purpose, methylcelluloses were prepared under homogeneous conditions (in dimethylacetamide DMAc/ $\% \mathrm{LiCl}$ as solvent) with different degrees of methylation (with iodomethane) and compared to commercial samples having nearly the same average degree of methylation (DS) [1,8]. Their behavior is completely different when temperature varies, indicating the strong influence of methyl group distribution along the cellulosic backbone. This work allows us to draw the following conclusions: aqueous commercial methylcellulose solution presents an LCST-type phase separation and the phase diagram demonstrated a critical point at a temperature $\mathrm{Tc}=29 \pm 2{ }^{\circ} \mathrm{C}$ and a polymer concentration $\mathrm{Cc}=45 \pm 5 \mathrm{~g} / \mathrm{L}$ with a Methocel A4C (DS $=1.7$ and $\mathrm{Mv}=149,000)$ [2] (Figure 1).

Figure 1. Phase diagram of an aqueous A4C methylcellulose solution (DS $=1.7$ from Dow Chemical) including the cloud point curve $(\square)$ and the sol-gel line ( $\square$ ) determined from oscillatory measurements [2]. Reproduced from Polymer 1998, 39, 6251-6259. Copyright 2010, Elsevier.

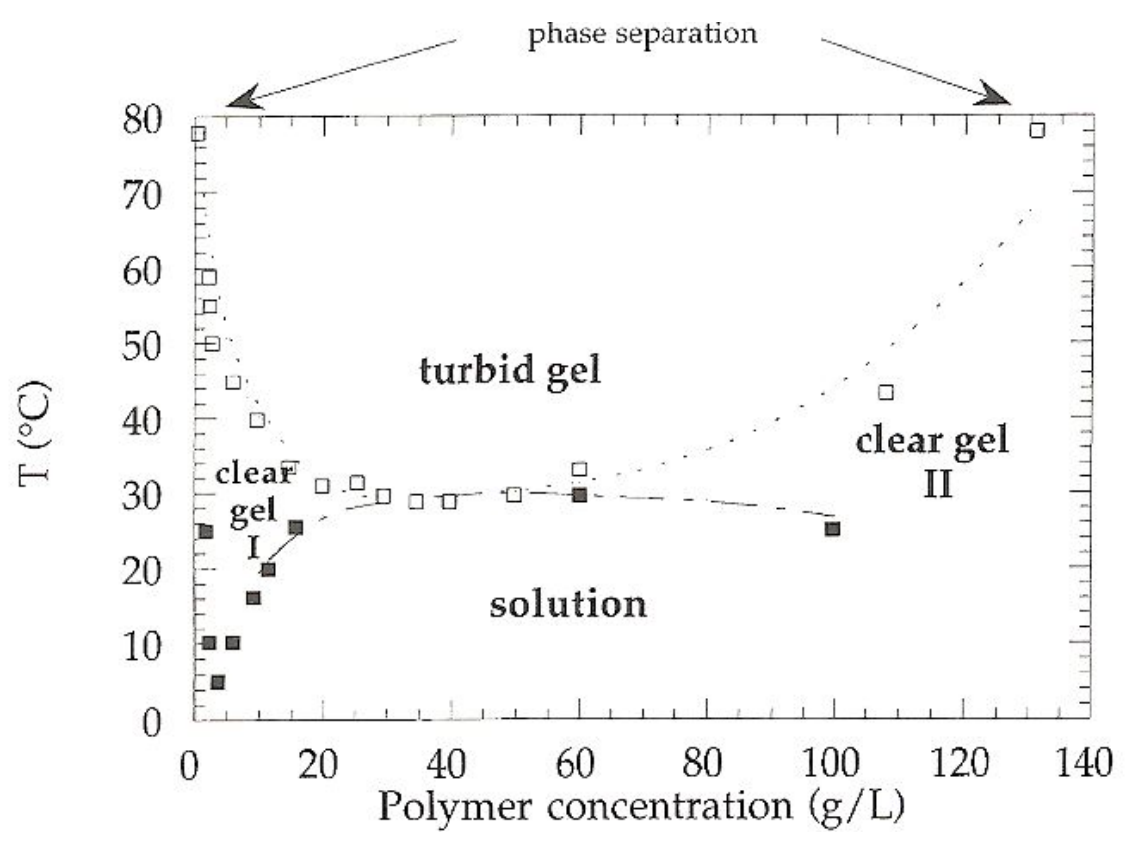


At low temperature $\left(\mathrm{T}<20^{\circ} \mathrm{C}\right)$, these methylcelluloses are water soluble in a large range of concentration; then, when temperature increases (over $35^{\circ} \mathrm{C}$ ), a clear gel is formed with an hysteresis in the storage and loss moduli ( $\mathrm{G}^{\prime}$ and $\mathrm{G}^{\prime}$ ') on cooling down.

This first step is attributed to the highly methylated zones forming the junctions of the $3 \mathrm{D}$ structure in the polymeric system. It is perfectly absent for homogeneously modified cellulose in the same range of substitution. Over $60{ }^{\circ} \mathrm{C}$, a turbid gel forms associated with a large increase of the storage modulus G'; this second step depends on the polymer concentration and on the external salt composition (see Figure 2) [2,8].

Figure 2. Influence of polymer concentration and temperature on the elastic modulus $G$ ' ( $\mathrm{Pa}$ at $1 \mathrm{~Hz}$ ) of $\mathrm{A} 4 \mathrm{C}$ solutions in water. Rate of temperature variation is $0.5 \% \mathrm{mn}$ [2]. Reproduced from Polymer 1998, 39, 6251-6259. Copyright 2010, Elsevier.

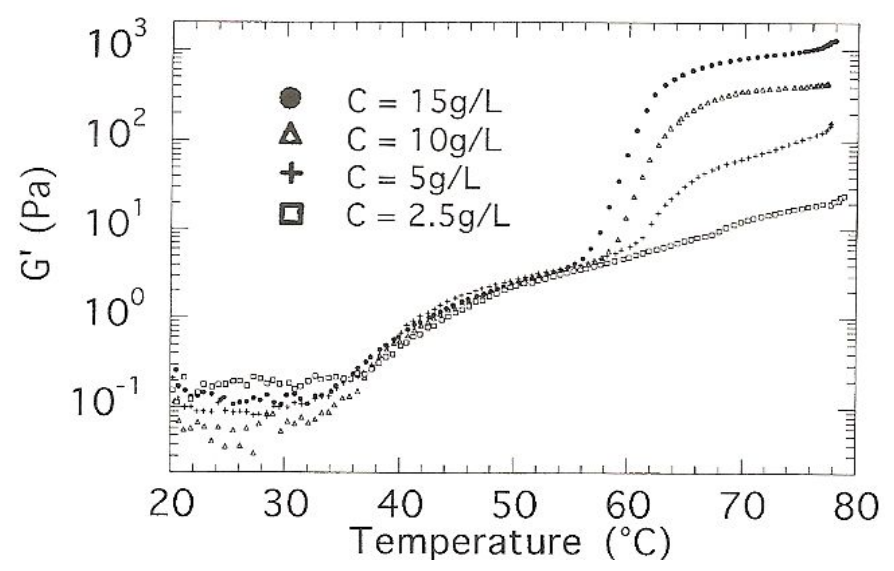

It corresponds to the phase separation leading to dense aggregates and gives a large hysteresis on cooling. On the contrary, with homogeneous methylcelluloses at the same average DS, increase in G' occurs progressively at higher temperature; only at $\mathrm{DS}=2.2$, a two steps mechanism is observed due to the presence of a large amount of trimethylated units $(43 \%$ of the glucose units are trimethylated) [8]. It is necessary to specify that gelation is a time dependent and reversible phenomena, the redissolution being less favorable than gelation from an energetical point of view [2].

In addition to the amphiphilic and gelling properties, oxidation of methylcellulose may be an interesting reaction to introduce aldehydic groups along the cellulosic chain to perform new reactions such as grafting of different molecules having one primary amine $[9,10]$ or crosslinking with different polyamines such as diamines or chitosan [11].

The objective of this paper is to prepare oxidized methylcelluloses with different degrees of oxidation, to characterize the new polymers obtained and to perform different reactions with amines using the well known reaction of reductive amination [12]. Especially, we intend to point out the influence of oxidation of methylcellulose on reactivity and physical properties of these oxidized methylcelluloses in relation to possible developments.

\section{Experimental Section}

Chitosan Kitomer provided by Marinard (Canada) was characterized by a degree of acetylation $\mathrm{DA} \sim 0.2$ and $\mathrm{Mw}=500,000$. Methylcellulose Methocel A15 Premium LV is produced by Dow 
Chemical (Mv 31500; DS 1.8); this sample was used for the study of oxidation by metaperiodate. HA-ADH was a gift from ARD company (Pomacle, France) and was prepared following a previously described method $[13,14]$. The synthesis was performed in presence of EDC at ambient temperature and $\mathrm{pH}=4.75$; after reaction, the product is purified by diafiltration in dilute solution $(1 \mathrm{~g} / \mathrm{L})$ and used directly; the initial weight-average molecular weight of HA is $300,000 \mathrm{~g} / \mathrm{mol}$.

Sodium metaperiodate, 3-aminopropionic acid ( $\beta$-alanine; $\left.\mathrm{NH}_{2}-\left(\mathrm{CH}_{2}\right)_{2}-\mathrm{COOH}\right)$ and sodium cyanoborohydride $\left(\mathrm{NaBH}_{3} \mathrm{CN}\right)$ were obtained from Sigma-Aldrich.

Oxidation was performed following the conditions adopted previously for alginates [15]: $2 \mathrm{~g}$ of polysaccharide were dissolved in $150 \mathrm{~mL}$ water, in a dark bottle; then, $50 \mathrm{~mL}$ of aqueous solution containing $264 \mathrm{mg}$ sodium periodate was added under stirring (molar ratio [glucose units]/[periodate] 10); assuming that one mole of periodate oxidizes one glucose unit, these conditions correspond to samples at $10 \%$ oxidation-or $10 \%$ of modified glucose units. The same reaction was performed with molar ratio equal to 10,4 and 2 which corresponded to the predicted degrees of oxidation of 10, 25 and 50\% (a maximum of one sugar unit was oxidized over two glucose units); the samples were also named ME 10, ME 25 and ME 50 respectively. This enabled studying the role of the degree of oxidation on the physical properties of the derivatives prepared. After 24 hours in dark at ambient temperature, the solutions of oxidized methylcelluloses (Me-ox) were dialyzed against pure distilled water, concentrated at $35{ }^{\circ} \mathrm{C}$ and freeze dried before characterization. Initial commercial methylcellulose was also purified in the same conditions. The degree of oxidation was controlled by infrared and NMR as discussed separately [11] and also determined quantitatively using the colorimetric technique with ferricyanide (yield in reducing groups using maltose to calibrate the response at $420 \mathrm{~nm}$ ) [16].

Elemental analysis was used to determine the yield in nitrogen in the different derivatives prepared. Such analyses are realized at "Service Central d'Analyses" (CNRS, Solaize-France).

For reaction with different amines, a given amount of reactant was added into a $20 \mathrm{~g} / \mathrm{L}$ oxidized methylcellulose aqueous solution (Me-ox); then, an excess of reducing agent $\left(\mathrm{NaBH}_{3} \mathrm{CN}\right.$ at a molar concentration five times the $-\mathrm{C}=\mathrm{O}$ content) was added to reduce the intermediate imine as shown previously to obtain a stable linkage $\mathrm{X}-\mathrm{NH}-\mathrm{CH}_{2}-\mathrm{R} \quad(\mathrm{R}-\mathrm{CH}=\mathrm{O}$ was used for the oxidized polysaccharide chain) [12]. After addition of the reducing agent (here $\mathrm{NaBH}_{3} \mathrm{CN}$ ), $\mathrm{pH}$ was stabilized at a value around 6 and left under stirring during 24 hours before isolation and purification. To prepare 3D- networks, oxidized methylcelluloses were added in their solid form in a solution of chitosan or hyaluronan-ADH $[11,13,14]$. After complete dissolution, the reductive agent was added and the method used was the same as described for simple amine.

${ }^{1} \mathrm{H}$ NMR experiments are performed using a Bruker DRX400 spectrometer operating at $400 \mathrm{MHz}$. 1D NMR spectra are collected at $30{ }^{\circ} \mathrm{C}$ using $32 \mathrm{~K}$ data points and 32 scans. Deuterium oxide (99.90\% D) was provided by Euriso-top (France).

Molecular weight of methylcellulose and oxidized methylcelluloses was obtained by size exclusion chromatography (SEC) using a Waters Alliance GPCV2000 (U.S.) equipped with three detectors on line: a differential refractometer, a viscometric detector, and a multi angle laser light scattering (MALLS) detector from Wyatt (U.S.). The concentration of the sample injected was $5 \mathrm{~g} / \mathrm{L}$ with an injection volume of $100 \mu \mathrm{L}$ using two columns in series (Shodex OH-pack 802 and 803); before injection, the samples were filtrated on a $0.2 \mu \mathrm{m}$ pore membrane ("Sartorius AG" cellulose acetate filter) in order to retain large 
aggregates. The eluent used was a $0.1 \mathrm{M} \mathrm{NaNO}_{3}$ aqueous solution, at $30{ }^{\circ} \mathrm{C}$ as elution temperature and a flow rate of $0.5 \mathrm{~mL} / \mathrm{min}$; the molecular weight distribution and weight-average molecular weight $\left(\mathrm{M}_{\mathrm{w}}\right)$ were determined using refractive index increment $\mathrm{dn} / \mathrm{dc}=0.142$.

Degree of swelling on chitosan-oxidized methylcellulose gels was calculated in different conditions from the ratio of weight of solvent engaged in the swollen material divided by the dry weight of the gel obtained after weight stabilization at $70{ }^{\circ} \mathrm{C}$.

The rheological behavior of methylcelluloses and their derivatives in solution was determined using an AR 2000 rheometer from "TA Instruments" (U.S.) at $25^{\circ} \mathrm{C}$ using a cone and plate geometry $(4 \mathrm{~cm}$ diameter plate with $3.59^{\circ}$ cone). Variable temperature runs, in a temperature range from 15 to $70{ }^{\circ} \mathrm{C}$, were performed when needed at a temperature variation rate of $3^{\circ} \mathrm{C} / \mathrm{min}$; temperature was controlled with the use of a Peltier plane. Dynamic experiments were performed in the linear viscoelastic region where G' and G' are independent on the frequency applied. Dynamic moduli (storage modulus G' and loss modulus $G^{\prime}$ in Pa), as well as complex viscosity $\left|\eta^{*}\right|$, were determined as a function of the angular frequency $(\omega)$ expressed in Hz. Steady state viscosity $\eta$ (in Pa.s) was determined as a function of the shear rate $\gamma$ (in s ${ }^{-1}$ ). Methylcellulose, oxidized methylcelluloses and loosely crosslinked HA were solubilized in water for rheology.

\section{Results and Discussion}

\subsection{Introduction to Polysaccharide Oxidation}

Oxidation of cellulose by sodium metaperiodate has been extensively investigated and was developed on many other polysaccharides; it produces a 2,3-dialdehyde along the chain allowing further chemical modification [17-21]. Other polysaccharides have been oxidized with metaperiodate, from which: (i) methylcellulose and hydroxyethyl cellulose [22-25] were produced for their hemostatic properties; (ii) guar and hydroxypropyl guar were oxidized to access the degree of substitution at secondary hydroxyls of hydroxypropyl guar [26]; (iii) alginates were oxidized at different rates and it was shown that the flexibility of the polysaccharide decreases in direct relationship of the opening of uronic acid [15,27,28]; (iv) dextran and scleroglucan were also oxidized with periodate [29-31]. It has been shown that only the unsubstituted glycol groups react with periodate in the same conditions, but other papers mentioned overoxidation of 2,3,2,6 and 3,6-dimethylglucoses [22,32]. In all cases, random chain scission is demonstrated [15,22].

The presence of aldehydic groups on polysaccharides (cellulose and its ethers) rich in hydroxyl groups induces crosslinkage and formation of hydrogels by reaction of $-\mathrm{OH}$ groups existing on the same chain or on different chains $[33,34]$.

It is also interesting to mention that other specific techniques may be used to oxidize polysaccharides such as TEMPO (2,2,6,6-tetramethyl-1-piperidinyloxy radical) [35,36] causing oxidation on the C6 position (up to the carboxylic function) or enzymes such as galactosidase used to oxidize galactomannan on the galactose unit [37].

Considering the interest in oxidation of polysaccharides, it can be considered as an intermediate form for specific chemical substitution on $\mathrm{C} 2$ and/or $\mathrm{C} 3$ positions of sugar units. Few examples are given in literature: (i) the aldehyde groups can react to label the polysaccharide [38,39]; (ii) aldehyde 
groups react with nucleophilic reactant such as hydroxylamine [19]; these authors showed that the two aldehydic groups react only with hydroxylamine; with other nucleophilic reagents, only half is modified; (iii) recently, oxidized methylcelluloses were used to crosslink chitosan [11], oxidized scleroglucan was crosslinked in presence of hexamethylenediamine [31] and oxidized dextran was crosslinked with adipic acid dihydrazide (30).

To conclude, oxidation of polysaccharides allows considerably modifying the physical behavior of the initial polymers and particularly their stiffness. The introduction of aldehyde groups also allows their derivatization and extends the possible applications in a controlled way.

\subsection{Characterization and Properties of Oxidized Methylcelluloses}

\subsubsection{Characterization}

First of all, the molecular weight distributions of initial methylcellulose and derivatives were determined by SEC and are shown in Figure 3.

Figure 3. Differential molecular weight distributions for methylcellulose and oxidized methylcelluloses (ME 10, ME 25, ME 50) obtained by steric exclusion chromatography (SEC).

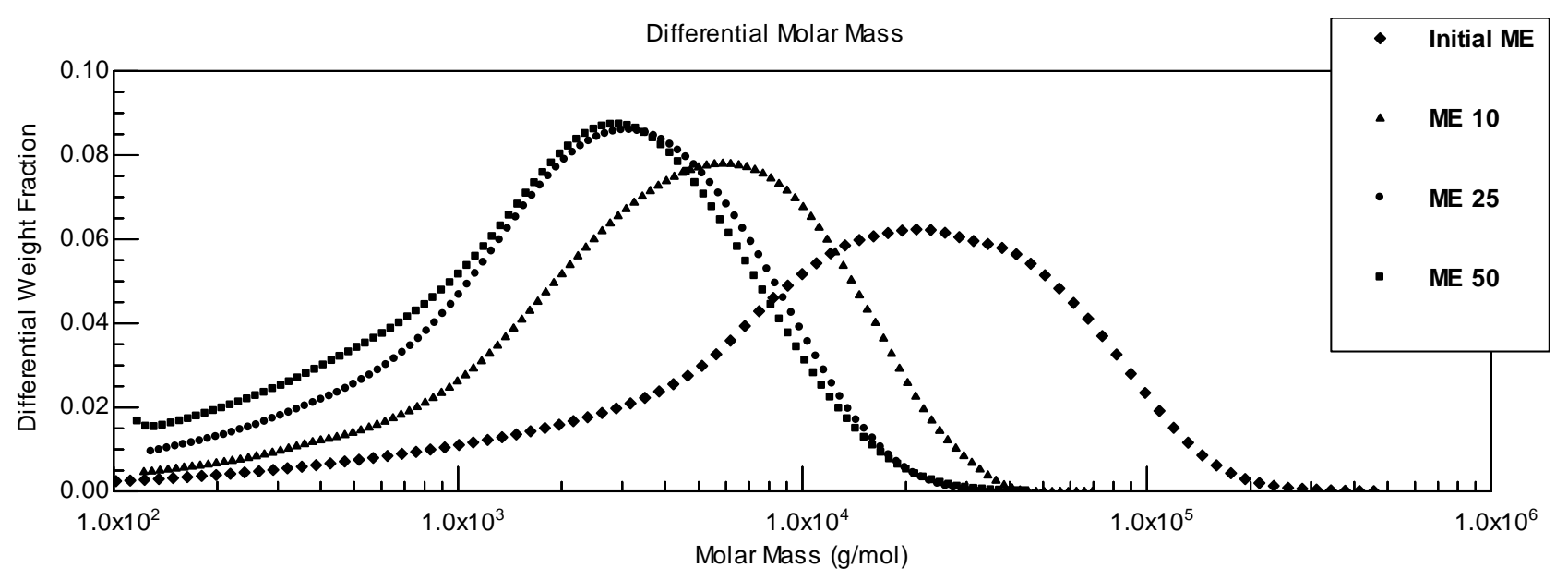

Depolymerization of methylcellulose during oxidation is clear; at 25 and $50 \%$ oxidation, molecular weights are low and in the same range of magnitude. The weight-average molecular weights and the intrinsic viscosity evolution are given in Figure 4. It is clear that the conditions for oxidation produce degradation of methylcellulose; similar results were obtained previously for the oxidation of alginates [15]. In addition, the stiffness of the molecule decreased due to the opening of anhydroglucose units; nevertheless, in our experimental conditions, the molecular weights are too low to permit a serious analysis of the persistence length as we did previously on alginates.

The second characteristic of these modified polysaccharides is the degree of oxidation. As discussed before, it is difficult to determine the exact number of reactive aldehydic groups due to secondary reactions in which aldehydes are engaged and first of all, various hydrated structures either intra- or intermolecularly [19-21]; nevertheless, using IRTF, it is shown that content in $-\mathrm{C}=\mathrm{O}$ from aldehydic groups at $1,735 \mathrm{~cm}^{-1}$ increases linearly up to $25 \%$ oxidation and then levels slightly off due to the 
presence of methylated and unreactive $-\mathrm{OH}$ in the $\mathrm{C}-2$ and $\mathrm{C}-3$ positions [11]. It was previously determined that $40 \%$ of the glucose units are dimethylated in C2 and C3 positions in the initial methylcellulose used [8].

Figure 4. Influence of the degree of oxidation on the weight-average molecular weight $(\mathrm{Mw})$ and on the intrinsic viscosity $([\eta]$ in $\mathrm{mL} / \mathrm{g})$ obtained by SEC with a multidetection.

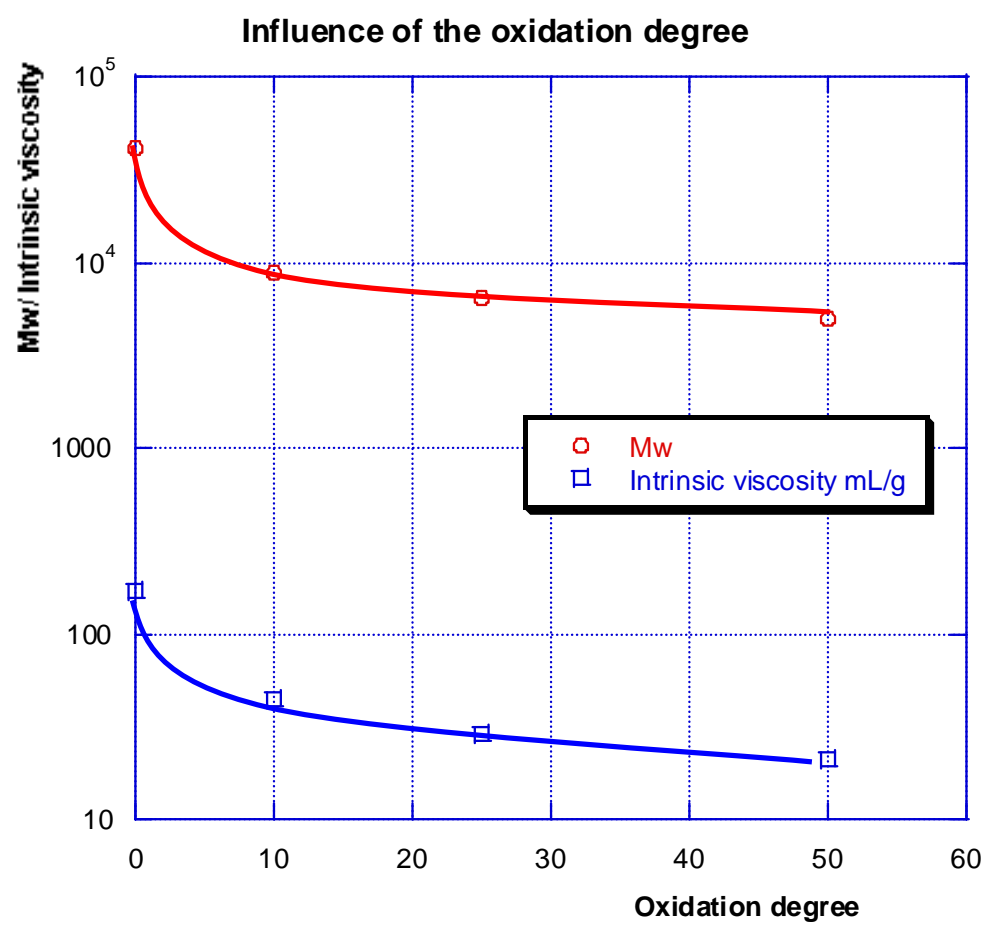

The direct titration of aldehyde groups [11] follows the IRTF results and gives, respectively, 4.5, 13.4 and $19.4 \%$ of glucose units oxidized (assuming the presence of two $\mathrm{C}=\mathrm{O}$ per oxidized sugar) [20]. This yield must correspond to the maximum of possible reaction between amine groups and $-\mathrm{C}=\mathrm{O}$. These characteristics of oxidized methylcelluloses were discussed in a previous paper [11].

${ }^{1} \mathrm{H}$ NMR also allowed us to follow the reaction of oxidation as previously shown, but on aging in the dry state, a modification of the spectrum was observed: in particular, the thin signal at $3.95 \mathrm{ppm}$ (attributed to $\mathrm{H} 1$ of oxidized units with opening of the cycle) disappeared, as did the signal at $3.4 \mathrm{ppm}$ (attributed to the proton of methyl groups on C6 of the same type of units) and the spectrum went back to that of the initial methylcellulose (Figure 5).

The small signals at 8.47 and $9.32 \mathrm{ppm}$ [see Figure 5(b)] were attributed to the proton of aldehydic sites [30]. At the same time, due to aging, partial insolubility occurs; solubility in water is recovered (at least partially) in presence of alkaline medium. In these conditions, the ${ }^{1} \mathrm{H}$ NMR spectrum almost recovered its initial state [Figures 5(b,d)]. This phenomenon, observed at a certain period of time (here around six months), is important because it may reduce the reactivity of oxidized methylcellulose (especially in acidic conditions); the decrease in chain mobility and cross-linkage between chains have been described in the literature [33,34]. The samples dissolved in aqueous solution at basic $\mathrm{pH}$ but an increase of the apparent molecular weight and of the intrinsic viscosity were observed; both evolutions indicate some residual cross-linkage in these samples after aging. No such variation was observed on initial methylcellulose. 
Figure 5. Influence of aging in solid state on the ${ }^{1} \mathrm{H}$ NMR spectrum of oxidized methylcellulose. (a) initial methylcellulose; (b) direct spectrum of $25 \%$ oxidized methylcellulose; (c) $25 \%$ oxidized methylcellulose after aging; (d) the same sample dissolved in presence of NaOD. Solvent: D2O; temperature $30^{\circ} \mathrm{C}$. Two arrows indicate the specific signals of oxidized methylcellulose (see $b$ and $d$ ).

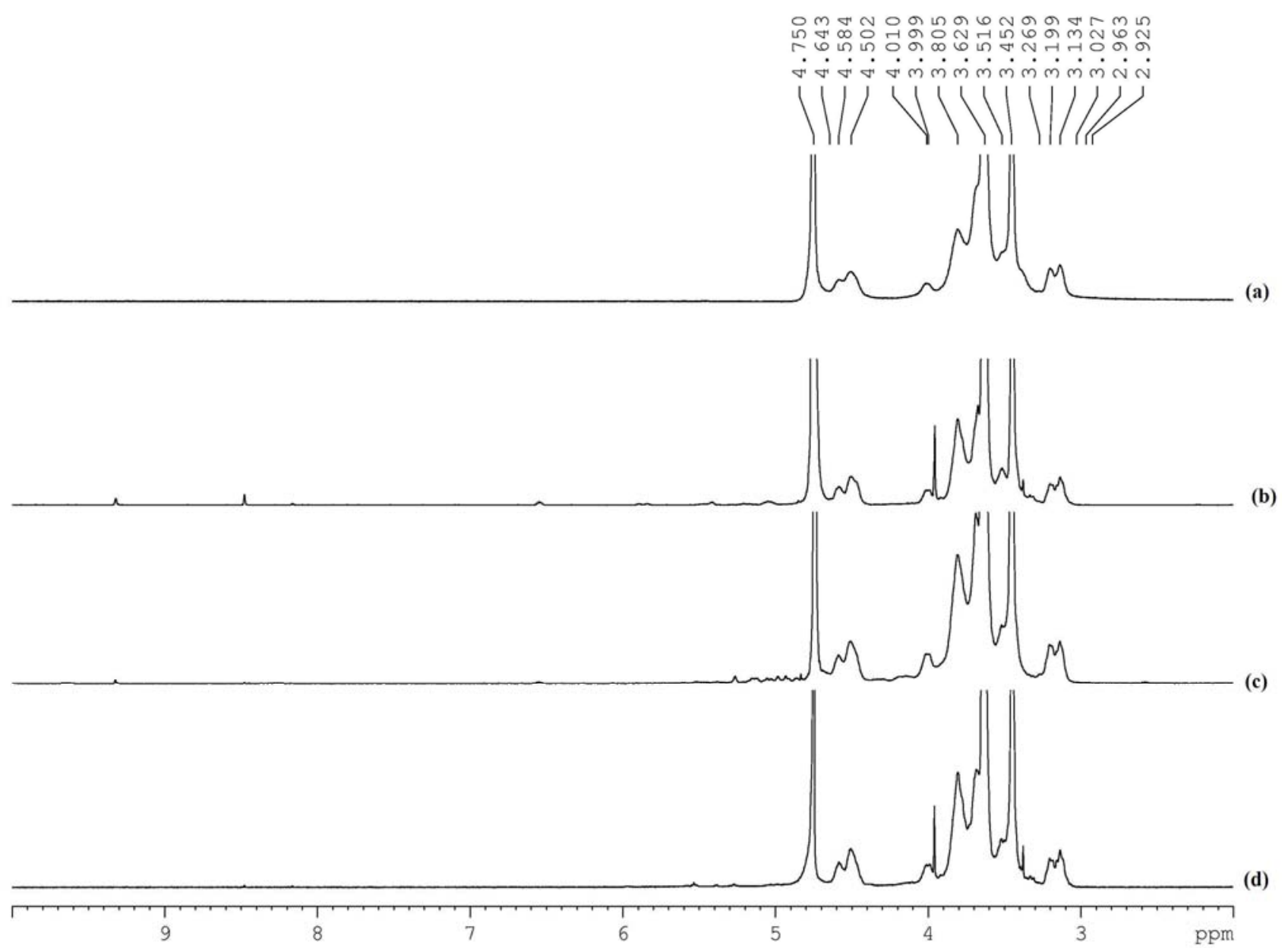

As a conclusion, it is clear that a large depolymerization exists during metaperiodate oxidation as was obtained in our laboratory with alginates [15]; in addition, secondary condensation reactions occur during aging of the oxidized methylcellulose under solid state reducing water solubility and aldehyde reactivity. The conditions of storage of the samples seem to be important when they need to be used for further reactions.

\subsubsection{Rheological Behavior of Methylcellulose.}

Methylcellulose behavior in aqueous solution is characteristic of amphiphilic systems; they are recognized as LCST polymers with a critical temperature Tc $29 \pm 2{ }^{\circ} \mathrm{C}$ [2]. They are soluble at low temperature (below $25^{\circ} \mathrm{C}$ ) but give a gel at higher temperature. For the specific methylcellulose sample used in this work and the experimental conditions adopted, the rheology is described in Figure 6; these data allow us to demonstrate the influence of oxidation on the rheological behavior of modified methylcelluloses. 
At $20^{\circ} \mathrm{C}, \mathrm{G}^{\prime}$ is lower than $\mathrm{G}^{\prime}$ ' in a large range of frequencies and the crossover point where $\mathrm{G}^{\prime}=\mathrm{G}^{\prime}$, is around $10 \mathrm{~Hz}$; in this regime, the complex viscosity was constant and equal to $0.046 \mathrm{~Pa}$.s. At $70{ }^{\circ} \mathrm{C}$, a gel-like behavior was obtained with $G^{\prime}>G^{\prime}$ ' in the whole frequency range covered. In addition, G' was very high $\left(\mathrm{G}^{\prime}=1,450 \mathrm{~Pa}\right)$ as was the ratio $\mathrm{G}^{\prime} / \mathrm{G}^{\prime}{ }^{\prime}=\sim 33$.

Figure 6. Dynamic moduli G' (storage modulus, filled symbols) and G', (loss modulus, open symbols) (expressed in $\mathrm{Pa}$ ) as a function of the frequency at $20{ }^{\circ} \mathrm{C}$ (solution: $\boldsymbol{\nabla}$ and $\nabla$ ) and $70{ }^{\circ} \mathrm{C}$ (turbid gel: $\mathrm{and} \bigcirc$ ). Concentration: $30 \mathrm{~g} / \mathrm{L}$ in water.

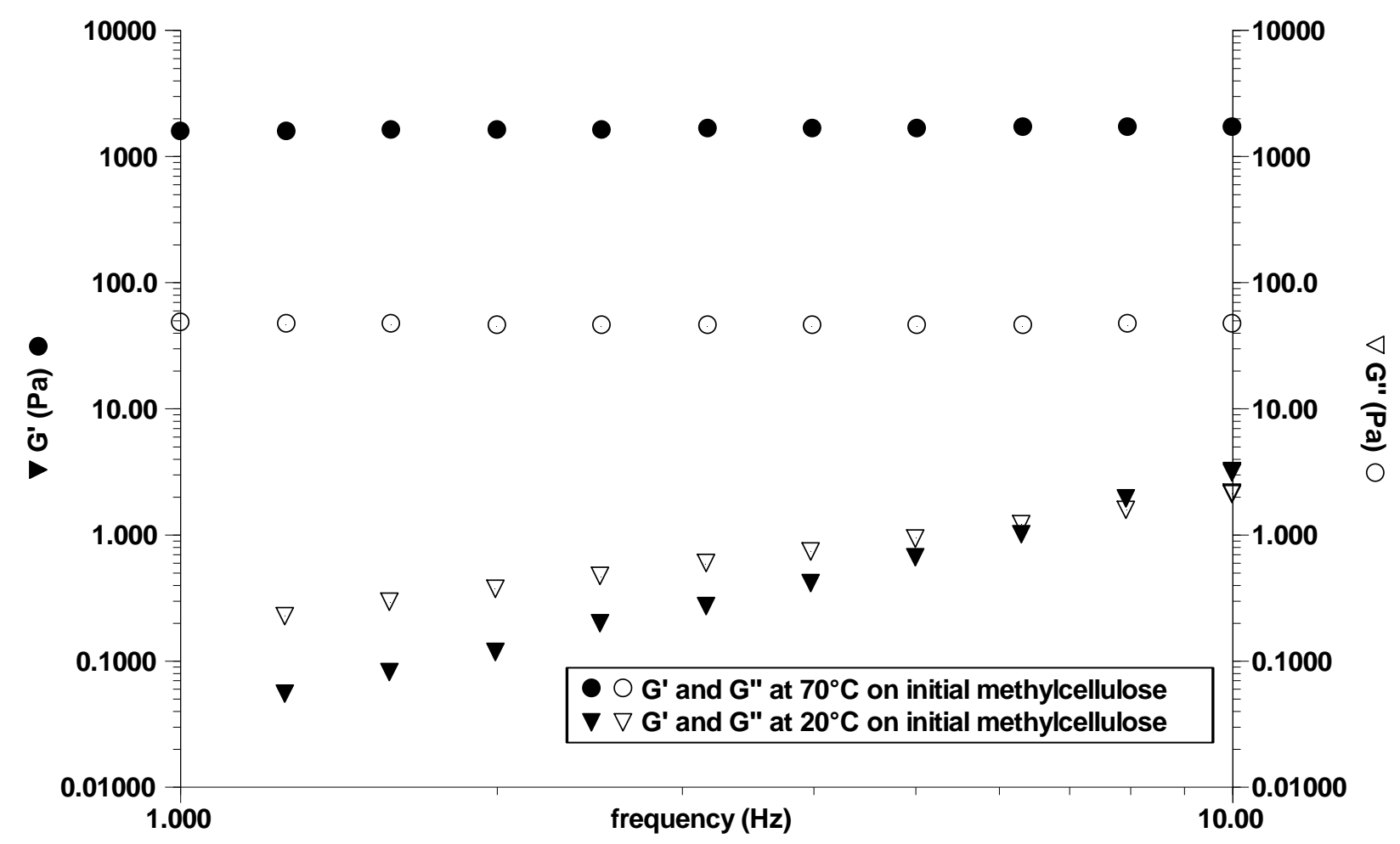

At high temperature, the complex viscosity was strongly non-Newtonian with a slope -0.986 ; as an example, the complex viscosity equals $227.8 \mathrm{~Pa} . \mathrm{s}$ at $1 \mathrm{~Hz}$. The change in behavior for a temperature cycle from $20{ }^{\circ} \mathrm{C}$ up to $70{ }^{\circ} \mathrm{C}$ and return is given in Figure 7 . When temperature increased, a cross point was obtained where $\mathrm{G}^{\prime}=\mathrm{G}^{\prime}$ ' (which may be considered in a first approach as a gel point) at a critical temperature $\operatorname{Tg} 29^{\circ} \mathrm{C}$, and G' became larger than $\mathrm{G}$ ', when entering in the domain of clear gel as introduced before [2]. On temperature decrease, a large hysteresis occurred and when the temperature reached $28^{\circ} \mathrm{C}, \mathrm{G}^{\prime}$ again became lower than $\mathrm{G}$ '. Then, even for a relatively low molecular weight, on increasing the temperature, the two steps mechanism was observed as described in our previous work: A clear gel formed over $30{ }^{\circ} \mathrm{C}$ and became stable between 40 and $55^{\circ} \mathrm{C}$; over $55^{\circ} \mathrm{C}$, a sharp increase in $\mathrm{G}^{\prime}$ revealed the phase transition to a turbid gel. 
Figure 7. G' and G', at $1 \mathrm{~Hz}$, as a function of the temperature. $\mathrm{G}^{\prime}(\bullet), \mathrm{G}^{\prime \prime}(\mathrm{O})$ on temperature increase from 20 to $70{ }^{\circ} \mathrm{C} ; \mathrm{G}^{\prime}(\boldsymbol{\nabla}), \mathrm{G}^{\prime}{ }^{\prime}(\nabla)$ on temperature decrease from 70 to $25{ }^{\circ} \mathrm{C}$. Concentration of initial methylcellulose: $30 \mathrm{~g} / \mathrm{L}$ in water. Temperature rate is $3 \% \mathrm{mn}$.

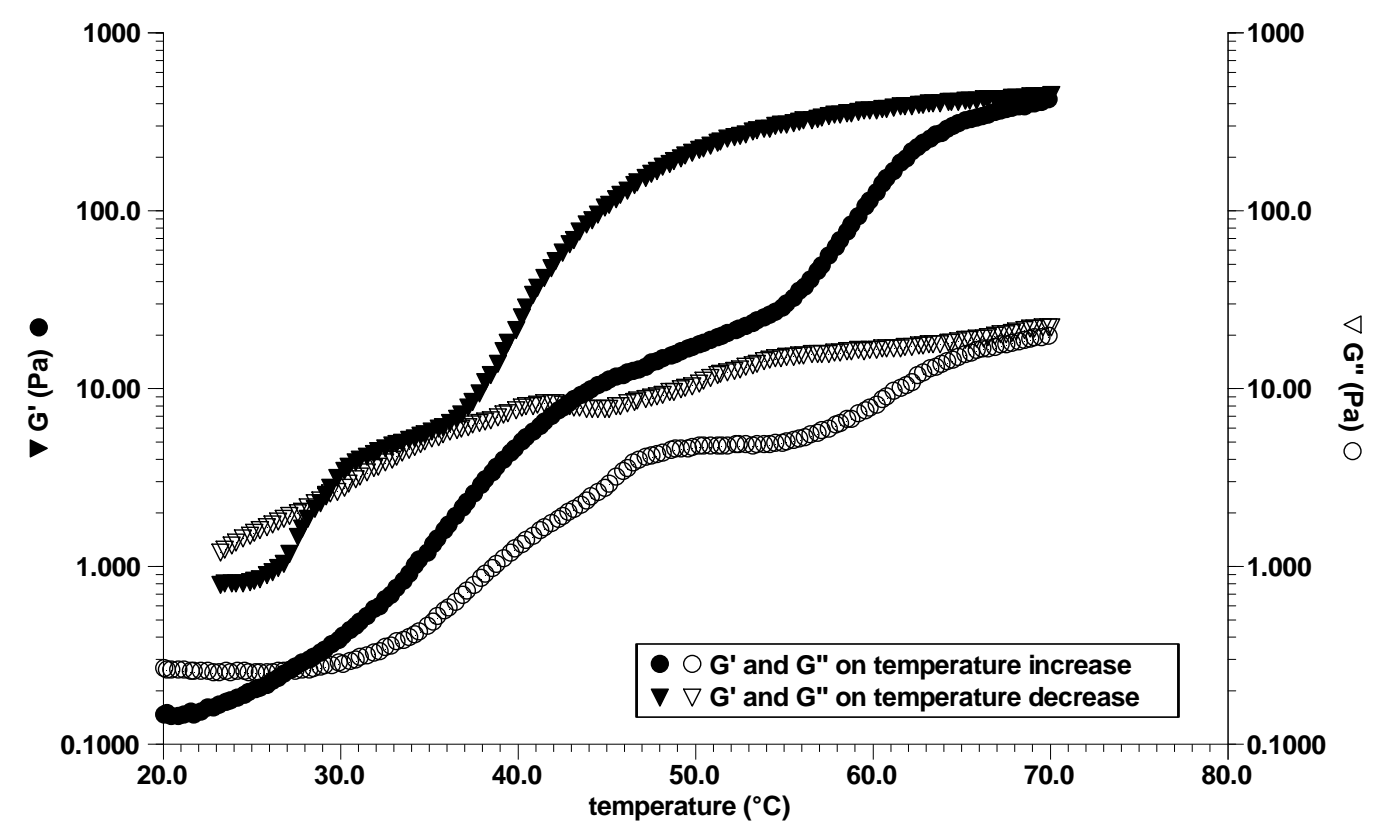

\subsubsection{Rheological Behavior of Oxidized Methylcelluloses}

All the experiments were performed at a polymer concentration of $30 \mathrm{~g} / \mathrm{L}$ in water. The rate of temperature variation imposed remains $3 \% / \mathrm{mn}$, which is rapid compared with some of our previous experiments (see Figure 2) and probably the values are not taken at equilibrium. Nevertheless our objective was only to compare the oxidized samples with the initial methylcellulose. At $15{ }^{\circ} \mathrm{C}$, all samples had G', $>G^{\prime}$ in the whole frequency range (sol behaviour) and the complex viscosity was Newtonian (Table 1).

Table 1. Dynamic rheology on $30 \mathrm{~g} / \mathrm{L}$ methylcellulose and derivative solutions in water. G' and G', moduli (expressed in $\mathrm{Pa}$ ) are determined at $1 \mathrm{~Hz}$.

\begin{tabular}{|c|c|c|c|c|c|}
\hline & $G^{\prime}$ at $15^{\circ} \mathrm{C}$ & $\mathrm{G}^{\prime \prime}$ at $15^{\circ} \mathrm{C}$ & $\mathrm{G}^{\prime}$ at $70^{\circ} \mathrm{C}$ & G' at $70^{\circ} \mathrm{C}$ & $G^{\prime} / G^{\prime \prime} 70^{\circ} \mathrm{C}$ \\
\hline Me cell Initial & 0.050 & 0.290 & 1500 & 47 & 32 \\
\hline ME 10 & 0.021 & 0.114 & 115 & 10.5 & 11 \\
\hline ME 25 & 0.032 & 0.126 & $25^{*}$ & $2.6^{*}$ & 10 \\
\hline ME 50 & 0.028 & 0.100 & $24 *$ & $2.8 *$ & 8.5 \\
\hline
\end{tabular}

* apparent values due to heterogeneity of the system.

At $70{ }^{\circ} \mathrm{C}$, for all the samples, $\mathrm{G}^{\prime}>\mathrm{G}^{\prime}$ ' and the storage and loss moduli remained independent of the frequency (see Figure 8). From the values in Table 1, it is shown that a transition in the oxidized methylcellulose behavior occurred over $10 \%$ oxidation; again, the samples ME 25 and ME 50 were very similar as obtained for molecular weight distribution; in fact, at $70{ }^{\circ} \mathrm{C}$, they formed macrogels at the polymer concentration used (and not a homogeneous continuous gel) in relation to their low molecular weights. 
Figure 8. Dynamic rheology at $70{ }^{\circ} \mathrm{C}$ for initial methylcellulose and the oxidized samples at $30 \mathrm{~g} / \mathrm{L}$ in water. ME 10 (10\% ox); ME 25 (25\% ox); ME 50 (50\% ox). G' (filled symbols) and G', (open symbols) expressed in Pa.

- $\bigcirc \mathrm{G}^{\prime}$ and $\mathrm{G}^{\prime}$ at $70^{\circ} \mathrm{C}$ on initial methylcellulose

$\nabla \nabla \mathbf{G}^{\prime}$ and $\mathbf{G}^{\prime \prime}$ at $70^{\circ} \mathrm{C}$ on $10 \%$ oxidized methylcellulose

$\Delta \triangle G^{\prime}$ and $\mathrm{G}^{\prime}$ at $70^{\circ} \mathrm{C}$ on $25 \%$ oxidized methylcellulose

$\square$ G' and G" at $70^{\circ} \mathrm{C}$ on $50 \%$ oxidized methylcellulose

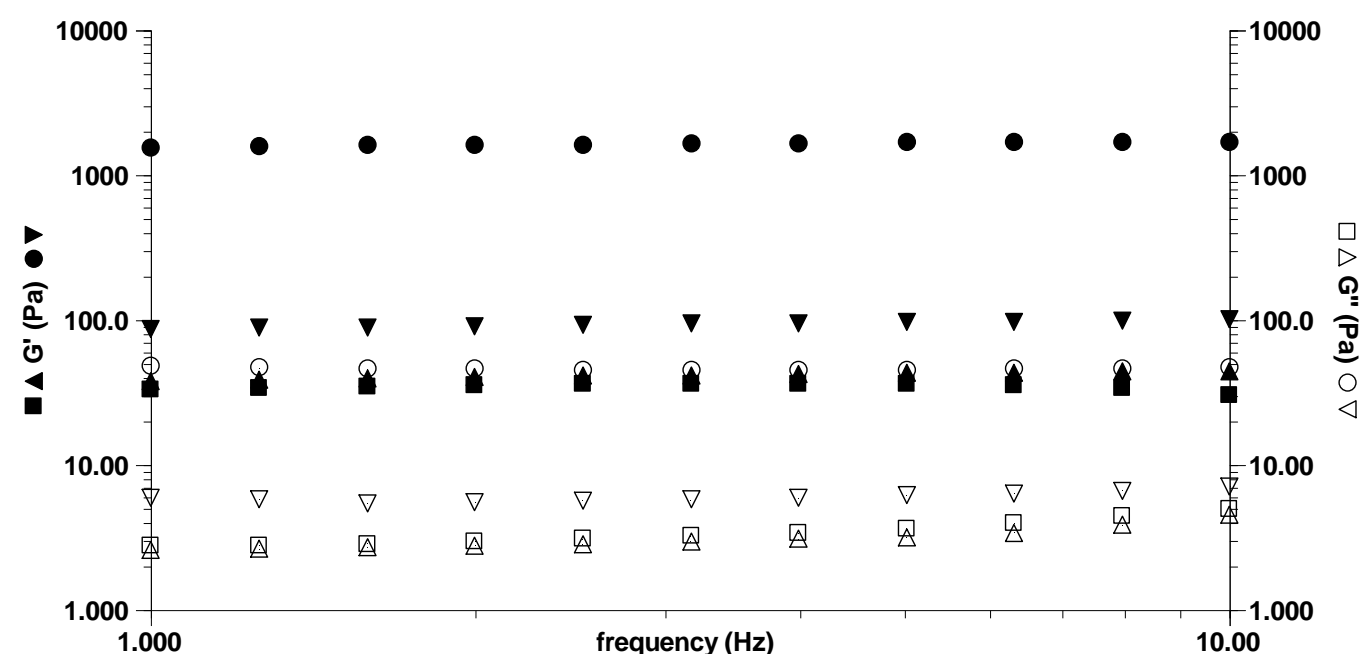

Considering a temperature cycle, it is clear that the behavior of ME 10 looks like that of the initial methylcellulose even if the moduli are lower at a given temperature (see Figure 9); but for a higher degree of oxidation, the second step in gelation is no longer present and the system looks heterogeneous as previously discussed.

Figure 9. Influence of temperature on the storage modulus G' $(\mathrm{Pa})$ of methylcellulose and oxidized derivatives at $30 \mathrm{~g} / \mathrm{L}$ in water. Filled symbols for increase of temperature; open symbols for decrease of temperature.

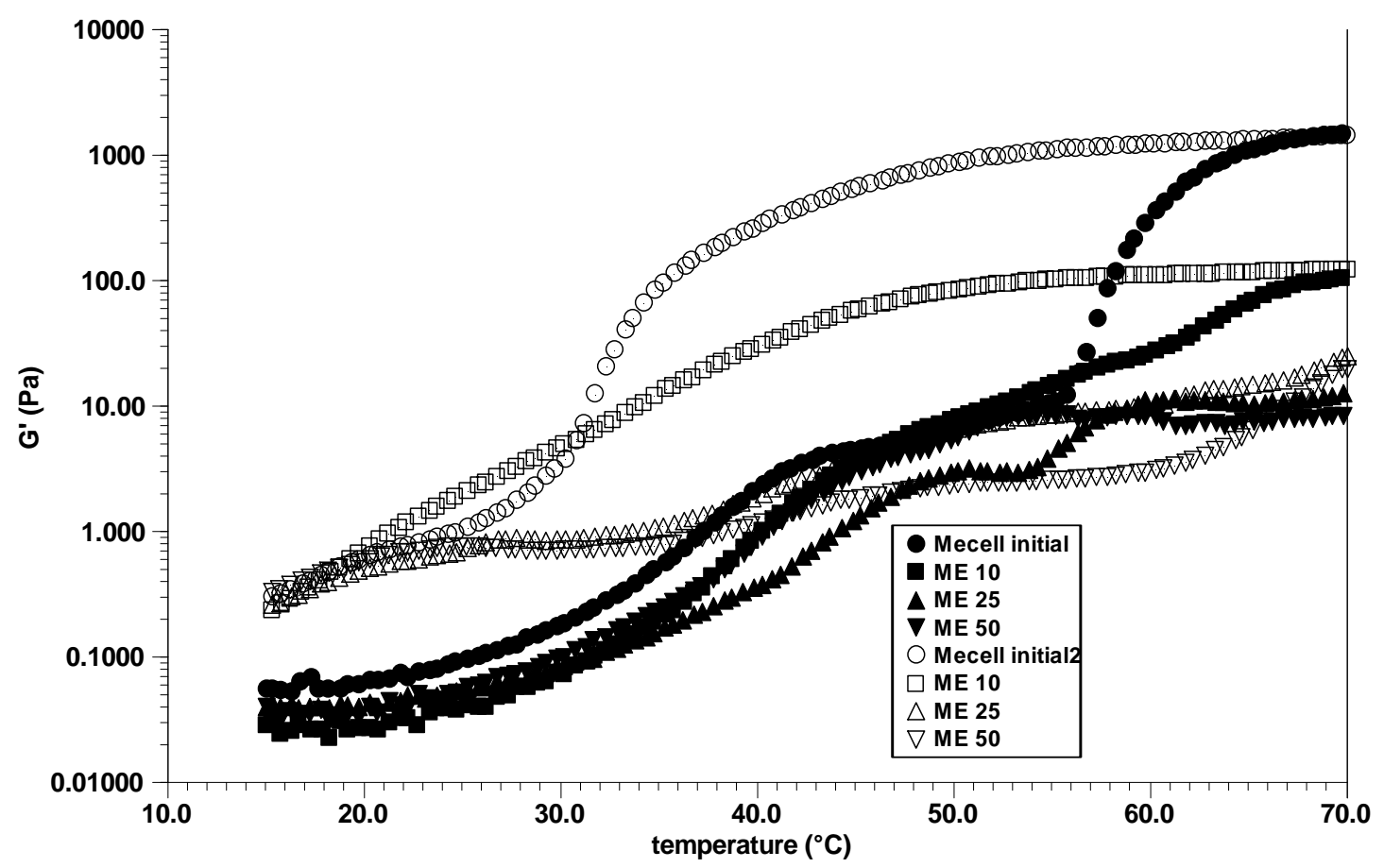


Additionally, $\mathrm{G}^{\prime}$ around $50^{\circ} \mathrm{C}$ (corresponding to the clear gel) was nearly independent of the degree of oxidation, which seems to indicate that the highly methylated zones were preserved during oxidation. Gelation was obtained even if the molecular weight was much reduced during oxidation; this result concurs with data obtained previously indicating that, for molecular weight variation from $\mathrm{Mw}=150,000$ to $410,000, \mathrm{G}^{\prime}$ and $\mathrm{G}^{\prime}$ ' as a function of temperature were nearly superposed [8].

This means that Mw did not have an essential role in the thermal rheological behavior which is mainly related to the chemical structure and methyl groups distribution along the cellulosic backbone. For all the samples, the G' modulus was higher after a thermal cycle due to the kinetic process of dissociation mentioned previously.

\subsection{Chemical Modification of Oxidized Methylcellulose}

The first modification performed was to introduce ionic groups on oxidized methylcellulose. For this purpose, $\beta$-alanine was reacted with the different oxidized methylcelluloses in the conditions of reductive amination described in the experimental section. After the reaction, the ionic derivatives were isolated by ultrafiltration on a cutoff membrane of 1,000 (to eliminate the excess of unreacted alanine and added salt) and characterized by SEC, NMR and elemental analysis. From elemental analysis, the nitrogen content obtained for the reaction involving ME 50 was $1.14 \%(\mathrm{w} / \mathrm{w})$ suggesting that $5.7 \%$ of the monomeric units were substituted on the $\mathrm{C} 2$ or $\mathrm{C} 3$ position. From ${ }^{1} \mathrm{H}$ NMR analysis (Figure 10), the signal at $2.6 \mathrm{ppm}$ was attributed to the proton of one $-\mathrm{CH}_{2}-$ from $\beta$-alanine; compared with the signals between 3 and 4 ppm, corresponding to the methylcellulose protons (at exclusion of $\mathrm{H}-1$ ), it comes $6.6 \%$ of the methylated glucose units being modified.

Figure 10. ${ }^{1} \mathrm{H}$ NMR spectrum of $\beta$-alanine grafted on ME 50 oxidized methylcellulose in $\mathrm{D}_{2} \mathrm{O}$ solution at $30^{\circ} \mathrm{C}$.

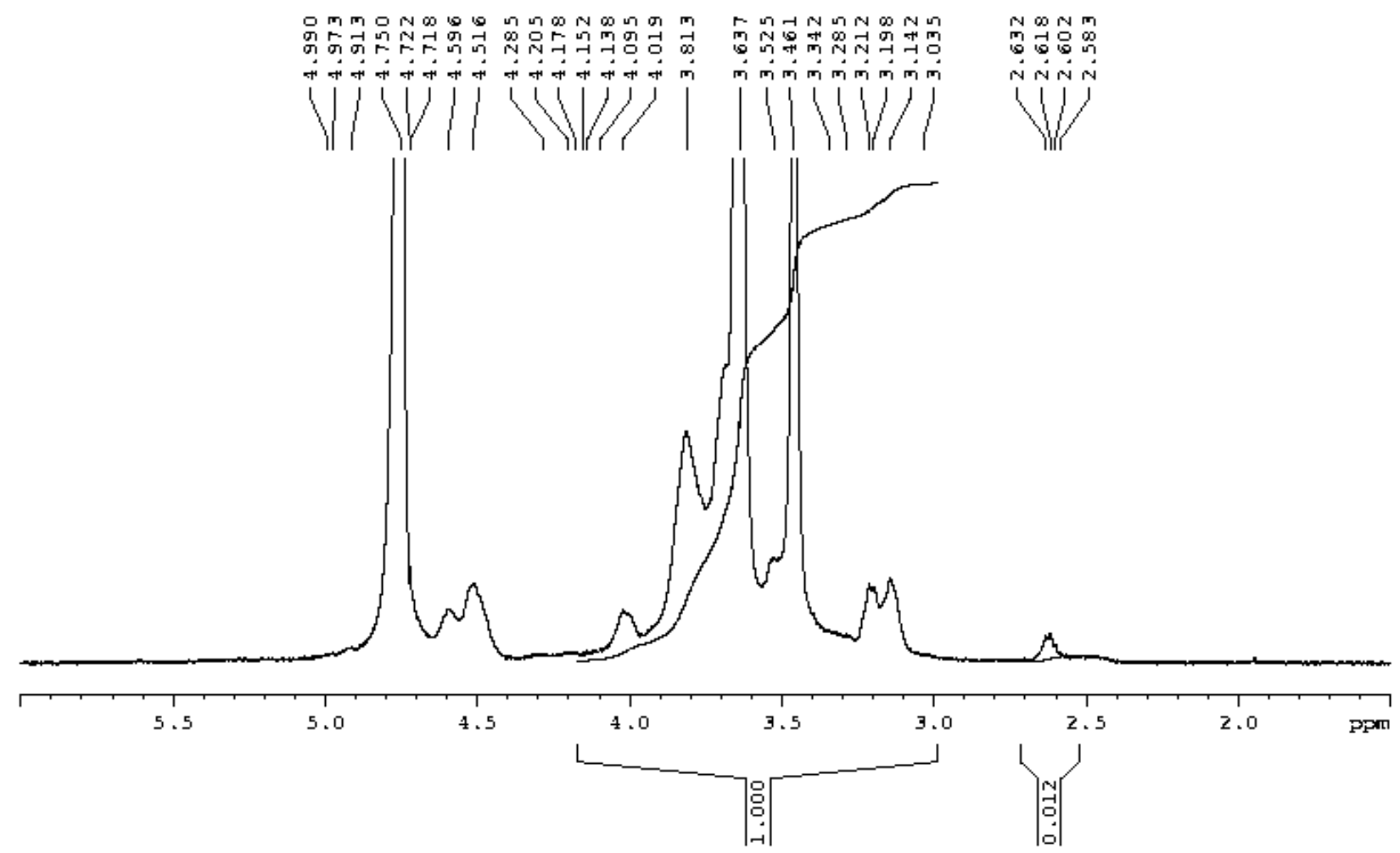


The agreement seems good but indicated a low reactivity of the aldehydic groups due to the secondary reaction mentioned previously. This result indicates the need to better control the conditions of reduction and possibly also the $\mathrm{pH}$ of the reaction. The solubility of this new derivative is good and SEC was successfully performed. The molecular weight of this derivative was nearly the same as that of the initial oxidized methylcellulose.

\subsection{Crosslinking of Chitosan and Hyaluronan with Oxidized Methylcellulose}

It was recently proposed to crosslink polysaccharides having $-\mathrm{NH}_{2}$ functions along the chain with polyaldehydic reactant; for that purpose, reductive amination was realized on chitosan reacting with different neutral oxidized polysaccharides (maltodextrins, galactomannan, and methylcellulose) [11].

We want to add complementary data upon application of this reaction on chitosan and on hyaluronan- $\mathrm{ADH}$; this $\mathrm{ADH}$ derivative permits control of the $-\mathrm{NH}_{2}$ yield along the $\mathrm{HA}$ backbone; usually it is around $8 \%$ of groups per disaccharide repeat unit in our work [13,14].

The first reaction was performed with chitosan in the presence of methylcellulose with different degrees of oxidation. The characterization of the hydrogels obtained is given in Table 2.

From elemental analysis, it is shown that, in the conditions adopted, the gel contained around 65\% chitosan in the different cases, with a very good reaction yield (more than $90 \%$ on the basis of total amount of polysaccharide introduced). The degree of swelling of the gels before any drying decreased when the degree of oxidation increased corresponding to a larger degree of crosslinkage. The gels are also rich in methylcellulose (around 35\%w/w) giving some amphiphilic character and compatibility [40]. In addition, a syneresis occurs directly during the gel preparation indicating a significant degree of crosslinkage.

Another series of reactions was performed in the presence of a larger amount of oxidized methylcellulose (ME 25); a larger degree of crosslinkage was obtained with a lower degree of swelling in water (compare Tables 2 and 3). Then, the degree of swelling was determined at different $\mathrm{pH}$ but in the presence of external salt: In acidic $\mathrm{pH}$, the protonation of chitosan increased but the external salt screened the electrostatic repulsion between positively charged chains.

The results indicate a low sensitivity on charge density of the network in relation, probably, with the high degree of cross-linkage. The predominant effect of the salt concentration on screening is shown in connection with the larger swelling degree in water than in presence of salt.

Table 2. Characterization of chitosan crosslinked with oxidized methylcelluloses *.

\begin{tabular}{|c|c|c|c|}
\hline Degree of oxidation & \% nitrogen & $\begin{array}{l}\text { Initial degree of swelling } \\
\text { in water }(\mathrm{g} / \mathrm{g})\end{array}$ & $\begin{array}{l}\% \mathrm{w} / \mathrm{w} \text { chitosan } \\
\text { in the gel } * *\end{array}$ \\
\hline ME 10 & 5.09 & 203 & 67 \\
\hline ME 25 & 5.44 & 146 & 65 \\
\hline ME 50 & 4.88 & 109 & 64 \\
\hline Initial chitosan & 7.56 & --- & \\
\hline
\end{tabular}

$* *$ Yield of reaction $\sim 90 \%$ on the basis of total polysaccharide engaged. 
Table 3. Swelling of chitosan-methylcellulose co-gel * at different $\mathrm{pH}$.

\begin{tabular}{ll}
\hline Medium & Degree of swelling $(\mathbf{g} / \mathbf{g})^{* *}$ \\
\hline water & 35.5 \\
PBS buffer $\mathrm{pH}=7.4$ & 30.2 \\
Citrate- $\mathrm{HCl}$ buffer $\mathrm{pH}=4$ & 25.4 \\
$0.15 \mathrm{M} \mathrm{NaCl}$ & 25.7 \\
chitosan solution at $12.5 \mathrm{~g} / \mathrm{L}+114 \mathrm{mg} \mathrm{ME} \mathrm{25;} \mathrm{final} \mathrm{pH}=6.4 ;{ }^{* *}$ without drying.
\end{tabular}

A similar type of experiment was developed on hyaluronan-ADH reacting with ME50; the initial solution was used as received at a low concentration $(1 \mathrm{~g} / \mathrm{L})(26.9 \mathrm{mg}$ of ME 50 added into $11 \mathrm{~mL}$ of solution). An example of experimental results is given in Figure 11, showing the viscosity as a function of the shear rate: at $1 \mathrm{~s}^{-1}$, the viscosity of the initial HA-ADH solution was 0.036 Pa.s but after reaction it became strongly non-Newtonian and equaled 37.3 Pa.s. In dynamic experiments, a loose gel behavior was demonstrated with a ratio G'/G' 26 at $1 \mathrm{~Hz}$. Nevertheless, HA was very loosely crosslinked, due to the low HA-ADH concentration used, and it was not possible to consider the gels in the dried state. More experiments are in progress to achieve stronger gels for new applications.

Figure 11. Influence of the crosslinkage on the viscosity measured as a function of the shear rate on HA -ME 50 copolymer. Solvent: water; temperature: $25^{\circ} \mathrm{C}$.

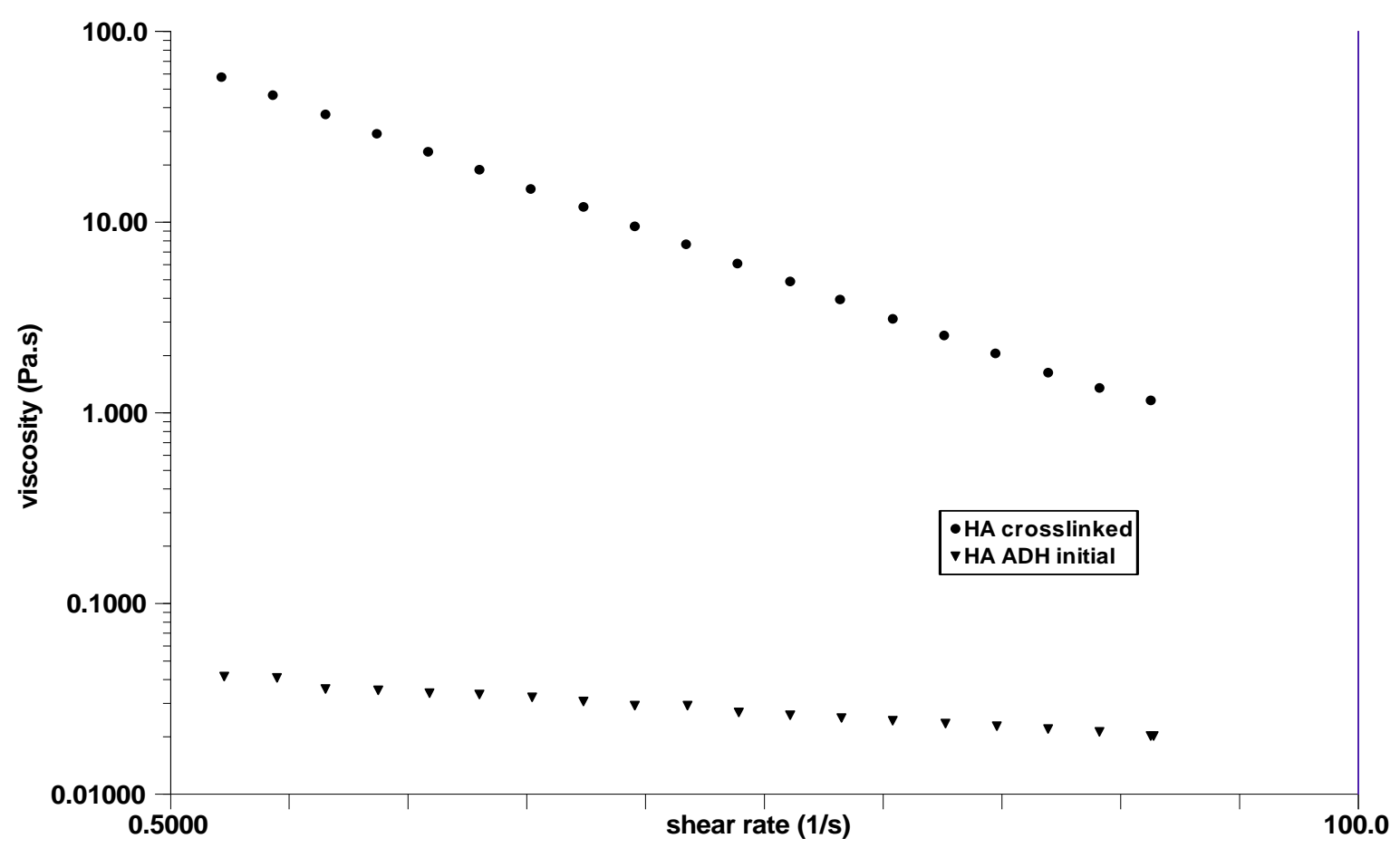

\section{Conclusions}

New oxidized methylcelluloses were prepared and characterized; all the experiments were performed on a low molecular weight initial methylcellulose $(\mathrm{Mw} 31,500)$ with the objective to reduce the viscosity of polymer mixtures when needed especially for crosslinking experiments. Different degrees of oxidation were prepared and characterized; it is clear that a large degradation 
occurs in the experimental conditions adopted especially for a degree of oxidation greater than $10 \%$. Whatever the degree of oxidation, the thermo-sensitive amphiphilic character remained (in relation to the stability of zones rich in highly methylated glucose units). A modification of the oxidized methylcelluloses during aging in the solid state at ambient temperature was demonstrated by ${ }^{1} \mathrm{H}$ NMR, which also modifies the water solubility. This is an important new piece of evidence which may have a role for further reaction. These new polyaldehydic derivatives are able to react by reductive amination in mild conditions (aqueous solution at $\mathrm{pH} 6$ ) with molecules having $-\mathrm{NH}_{2}$ functions. Few examples are given: (i) the reaction of $\beta$-alanine to obtain a negatively charged polyelectrolyte with good solubility; (ii) crosslinkage of polysaccharides rich in $-\mathrm{NH}_{2}$ such as chitosan and hyaluronan-ADH to produce hydrogels.

These new systems open the way to extend application of natural polysaccharides; especially, the biocompatibility and biodegradability of the networks prepared associated with an amphiphilic character can be well adapted for pharmaceutical, biomedical or cosmetic applications.

\section{Acknowledgements}

A. Bresin from ARD Cy (Pomacle, France) is acknowledged for the gift of HA and HA-ADH samples. The author thanks I. Jeacomine for technical assistance in NMR experiments

\section{References}

1. Hirrien, M.; Desbrieres, J.; Rinaudo, M. Physical properties of methylcelluloses in relation with the conditions for cellulose modification, Carbohydr. Polym. 1996, 31, 243-252

2. Hirrien, M.; Chevillard, C.; Desbrieres, J.; Axelos, M.A.; Rinaudo, M. Thermogelation of methylcelluloses: new evidence for understanding the gelation mechanism. Polymer 1998, 39, 6251-6259.

3. Heymann, E. Sol-gel transformation.I.The inverse sol-gel transformation of methylcellulose in water. Trans. Faraday Soc. 1935, 31, 846-864.

4. Arisz, P.W.; Kauw, H.J.J.; Boon, J.J. Substitution distribution along the cellulose backbone in O-methylceluloses using GC and FAB-MS for monomer and oligomer analysis. Carbohydr. Res. 1995, 271, 1-14.

5. Vigouret, M.; Rinaudo, M.; Desbrieres, J. Thermogelation of methylcellulose in aqueous solutions. J. Chim. Phys. 1996, 93, 858-869.

6. Desbrieres, J.; Hirrien, M.; Rinaudo, M. A calorimetric study of methylcellulose gelation. Carbohydr. Polym. 1998, 37, 145-152.

7. Desbrieres, J.; Hirrien, M.; Rinaudo, M. Relation between the conditions of modification and the properties of cellulose derivatives: thermogelation of methylcellulose. In Cellulose Derivatives: Modification, Characterization, and Nanostructures; Heinze, T., Glasser, W.G., Eds.; ACS Symp. Series 688; American Chemical Society: Washington, DC, USA, 1998; pp. 332-348.

8. Hirrien, M. Comportement des Méthylcelluloses en Relation avec Leur Structure. Ph.D. Thesis, Grenoble University I, Grenoble, France, 1996.

9. Yalpani, M.; Hall, L.D. Some chemical and analytical aspects of polysaccharide modifications. 3. Formation of branched-chain, soluble chitosan derivatives. Macromolecules 1984, 17, 272-281. 
10. Hall, L.D.; Holme, K.R. Tailored rheology : chitosan derivatives with branched pendant sugar chain. J. Chem. Soc. Chem. Commun. 1986, 3, 217-218.

11. Rinaudo, M. New way to crosslink chitosan in aqueous solution. Eur. Polym. J. 2010, 46, 1537-1544.

12. Hutchins, R.O.; Natale, N.R. Cyanoborohydride. Utility and applications in organic synthesis. A review. Org Prep. Proced. Int. 1979, 11, 201-246.

13. Creuzet, C.; Kadi, S.; Rinaudo, M.; Auzely Velty, R. New associative systems based on alkylated hyaluronic acid. Synthesis and aqueous solution properties. Polymer 2006, 47, 2706-2713.

14. Rinaudo, M.; Auzely, R.; Kadi, S.; Bresin, A.; Kubik, E. New Derivatives of Hyaluronic Acid, Their Preparation Process and Their Uses; Patent No. WO2007059890, 2007.

15. Gomez, C.G.; Rinaudo, M.; Villar, M.A. Oxidation of sodium alginate and characterization of the oxidized derivatives. Carbohydr. Polym. 2007, 67, 296-304.

16. Kidby, D.K.; Davidson, D.J. Convenient ferricyanide estimation of reducing sugars in the nanomole range. Anal. Biochem. 1973, 55, 321-325.

17. Varma, A.J.; Kulkarni, M.P. Oxidation of cellulose under controlled conditions. Polym. Degrad. Stab. 2002, 77, 25-27.

18. Maekawa, E.; Koshijima, T. Properties of 2,3-dicarboxy cellulose combined with various metallic ions. J. Appl. Polym. Sci. 1984, 29, 2289-2297.

19. Sarymsakova, A.A.; Nadzhimutdinov, Sh.; Tashpulatov, Yu.T. Chemical transformations in the chains of cellulose dialdehydes and cellulose ethers. Chem. Nat. Compd. 1998, 34, 170-174.

20. Roberts, H.J. Nondegradative reactions of starch. In Starch: Chemistry and Technology; Whistler, R.L., Paschall, E.F., Eds.; Academic Press: London, UK, 1965; Volume 1, pp. 470-472.

21. Whistler, R.L.; Daniel, J.R. Molecular structure of starch. In Starch: Chemistry and Technology, 2nd ed.; Whistler, R.L., BeMiller, J.N., Paschall, E.F., Eds.; Academic Press: San Diego, CA, USA, 1984; pp 174-177.

22. Gibbons, G.C. Periodate oxidation of water-soluble methylcellulose and its constituent methylglucoses. J. Textile Inst. Trans. 1956, 47, T511-T529.

23. Pendharkar, S.; Guo, J.X. Biodegradable Hemostatic Wound Dressings Containing Hemostatic Fabrics and Oxidized Polysaccharides; EP 1481694 A1 20041201, 2004.

24. Pendharkar, S.M.; Wissing, W.K. Wound Dressing Containing Aldehyde-Modified Regenerated Polysaccharide; U.S. Pat. Appl. Publ. US 2004101547 A1 20040527, 2004.

25. Wiseman, D.M.; Saferstein, L.; Wolf, S. Bioabsorbable Medical Devices from Oxidized Polysaccharides; U.S. Pat. Appl. Publ. US 2003073663 A1 20030417, 2003.

26. Ye, Y.Q.; Ding, B.; Wang, K.; He, J.P.; Cui, J.J.; Jiang, B. Determination of the degree of substitution at secondary hydroxyls of hydroxypropyl guar gum by periodate oxidation. Gaodeng Хиехіао Ниахие Хиеbao 2009, 30, 835-840.

27. Lee, K.Y.; Bouhadir, K.H. Mooney DJ, Evaluation of chain stiffness of partially oxidized polyguluronate. Biomacromolecules 2002, 3, 1129-1134.

28. Andresen, I.L.; Painter, T.; Smidsrod, O. Concerning the effect of periodate oxidation upon the intrinsic viscosity of alginate. Carbohydr. Res. 1977, 59, 563-566.

29. Cohen, J.D.; Chenault, H.K.; Schiffino, R.S. Preparation of Polysaccharide Dialdehydes Having High Purity; PCT Int. Appl. WO 2008133847 A1 20081106, 2008. 
30. Maia, J.; Ferreira, L.; Carvalho, R.; Ramos, M.A.; Gil, M.H. Synthesis and characterization of new injectable and degradable dextran-based hydrogels. Polymer 2005, 46, 9604-9614.

31. Maeda, H.; Rambone, G.; Coviello, T.; Yuguchi, Y.; Urakawa, H.; Alhaique, F.; Kajiwara, K. Low-degree oxidized scleroglucan and its hydrogel. Int. J. Biol. Macromol. 2001, 28, 351-358.

32. Nadzhimutdinov, S.; Sarymsakov, A.A.; Usmanov, K.U. Regularities in the synthesis of cellulose dialdehyde and its ethers. Cellul. Chem. Technol. 1981, 15, 613-628.

33. Perplies, E. Production of Temporarily Crosslinked Cellulose Ethers by Selective Oxidation of Hydroxyl Groups and Subsequent Crosslinking; PCT Int. Appl. WO 2003097700 A1 20031127, 2003.

34. Sarymsakov, A.A.; Nadzhimutdinov, S.; Usmanov, K.U. Crosslinking of oxidized cellulose. Uzb. Khim. Zh. 1975, 19, 45-48.

35. Sierakowski, M.R.; Milas, M.; Desbrieres, J.; Rinaudo, M. Specific modifications of galactomannans. Carbohydr. Polym. 2000, 42, 51-57.

36. Jiang, B.; Drouet, E.; Milas, M.; Rinaudo, M. Study on TEMPO-mediated selective oxidation of hyaluronan and the effects of salt on the reaction kinetics. Carbohydr. Res. 2000, 327, 455-461.

37. Frollini, E.; Reed, W.F.; Milas, M.; Rinaudo, M. Polyelectrolytes from polysaccharides: selective oxidation of guar gum —A revisited reaction. Carbohydr. Polym. 1995, 27, 129-135.

38. Hall, L.D.; Yalpani, M. Synthesis of luminescent probe-sugar conjugates of either protected or unprotected sugars. Carbohydr. Res. 1980, 78, C4-C6.

39. Christiansen, K.A.; Balance, S.; Potthast, A.; Chistensen, B.E. An evaluation of tritium and fluorescence labelling combined with multi-detector SEC for the detection of carbonyl groups in polysaccharides. Carbohydr. Polym. 2009, 76, 196-205.

40. Rinaudo, M. Main properties and current applications of some polysaccharides as biomaterials. Polym. Int. 2008, 57, 397-430.

(C) 2010 by the authors; licensee MDPI, Basel, Switzerland. This article is an open access article distributed under the terms and conditions of the Creative Commons Attribution license (http://creativecommons.org/licenses/by/3.0/). 